\title{
Silicon photonic grating coupler for monitoring optical emission of plasma
}

\author{
${ }^{1}$ Minhee Lee, ${ }^{2}$ Sung Chul Kim and ${ }^{1}$ Sang Jeen Hong \\ ${ }^{1}$ Department of Electronic Engineering, Myongji University, Korea \\ ${ }^{2}$ Department of Information \& Communication Engineering, Myongji \\ University, Korea
}

Received: 25.09 .2018

\begin{abstract}
An optical waveguide and a grating coupler based on silicon photonics are designed and fabricated. The device is intended for monitoring the spectral line $777 \mathrm{~nm}$ of oxygen plasma, which corresponds to electron relaxation of oxygen atoms in the plasma. To provide a maximum surface-coupling efficiency, we optimize the thickness of silicon-oxide cladding and the geometry of the grating coupler, using finite differential time-domain simulations. Two methods are used when fabricating a silicon photonic chip, a micro-fabrication with electron-beam lithography and a semiconductor-based process that employs a $248 \mathrm{~nm}$ optical lithography technology. We suggest our coupler as a conceptual approach to onwafer photon-collecting devices designed for studying glow-discharge plasmas.
\end{abstract}

Keywords: silicon photonics, plasma monitoring, plasma emission spectroscopy, sensors

PACS: $85.60 .-\mathrm{q}$

UDC: 621.3

\section{Introduction}

A great number of techniques have been suggested for controlling plasma uniformity and wafer uniformity, including modifications of gas diffusers, shower-head geometry, geometrically symmetric chambers and multi-zone electrostatic chucks with radio-frequency power. It is often very important that the plasma inside a chamber be uniformly distributed in a vacuum system. For more than two decades, wafer uniformity is of a great interest in plasma etching [1, 2]. In particular, its microscopic uniformity associated with the extreme edges of wafers still remains a great challenge $[3,4]$.

Macroscopic uniformity of wafers is affected by electrical and chemical discontinuity of plasma [5]. Gradient-potential bending in a plasma sheath near edge ring can cause a potential electrical discontinuity, while a chemical-concentration gradient available near the wafer edge due to lower reactant consumption than that in the centre of the wafer can produce a chemical discontinuity. Thermal discontinuity at the heated edge ring can also influence chemical reactions in a wafer-extreme-edge region. Thus enhancing the macroscopic plasma uniformity is a primary goal and numerous etching-process steps are applied during chip-integration flow. Moreover, the researchers are now interested in monitoring plasma processes using in-situ sensors, in order to match the plasma uniformity with the wafer uniformity [6, 7]. Optical emission spectroscopy represents a non-invasive technique for monitoring the intensity of plasma emission, which has been widely used for diagnosing plasma and monitoring its processes. Its role is important at least due to a lack of methods for direct monitoring of the plasma uniformity by observing the plasma through some viewing ports. The present research has been motivated by the needs of direct monitoring for the plasma-emission intensity from inside a working chamber. 
Note that the modern semiconductor-manufacturing industry is reluctant to introduce unknown or unproved materials in the processes that occur in vacuum chambers. In part, this is due to possible cross-contamination of the appropriate materials, which can worsen a manufacturing yield. It is worthwhile in this respect that silicon photonic devices usually employ conventional and well-known materials (e.g., silicon, silicon oxide and silicon nitride), and the methods for their fabrication are compatible with the underlying fabrication technique [8]. Then a silicon photonic grating coupler would have a great advantage in fabricating on-wafer optical sensors inside the plasma chamber. Depending on its geometry, this type of grating coupler can accept selectively vertically injected light, whereas a silicon-nitride waveguide with a siliconoxide cladding can efficiently transmit visible light $[8,9]$.

\section{Optical emission of plasma}

More than $60 \%$ of the steps entailed in processing of wafers involve plasma. Positive ions are created by removing electrons located at outermost energy levels. Then they interact with the surface materials to form volatile products during etching process, remove surface materials and material precursors during deposition, and form solid thin films. Strong electric fields applied to gaseous species cause gas molecules to be ionized, while the atoms are ionized or excited by colliding electrons. The excited atoms are very unstable and tend to become located at lower energy states. According to a collision-radiative model, these excitation and relaxation processes can be observed during plasma-glow discharge. The amount of the released energy can be quantified by the amount of the observed photon energy, when considering properly the emission spectrum (see Fig. 1). Analysis of the optical emission with spectroscopic techniques can reveal the information about atomic interactions in gaseous phases, so that the optical emission spectroscopy is the most preferred method for monitoring various processes in plasmas [10, 11].
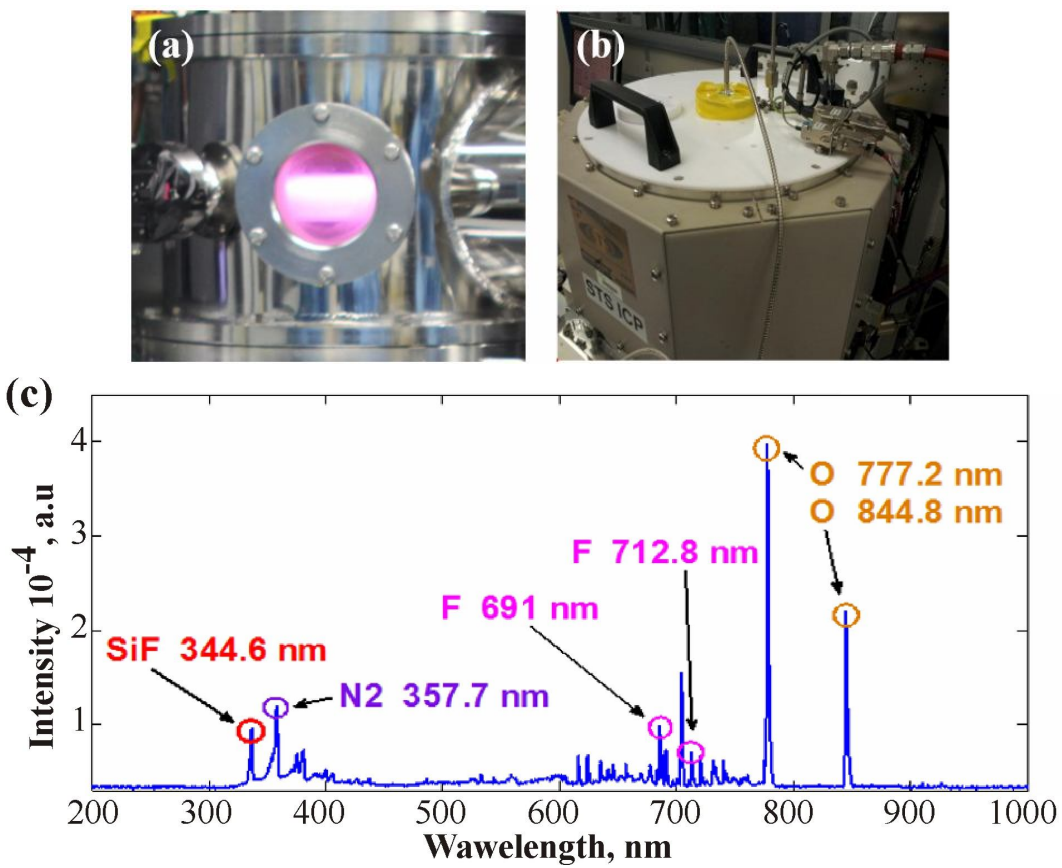

Fig. 1. Plasma-glow discharge and its monitoring with optical emission spectroscopy: (a) plasma emission, (b) optical monitoring of the plasma via a viewing port, and (c) sample optical emission spectra corresponding to different chemical species in the plasma.

Ukr. J. Phys. Opt. 2018, Volume 19, Issue 4 
To reveal spectral emission lines of gaseous species in the plasma-etching systems under study, we have collected optical spectroscopy data for different individual gaseous injections in the vacuum chamber. A 6-inch inductively coupled plasma-reactive ion-etching system that uses the radio-frequency power $300 \mathrm{~W}$ at $13.56 \mathrm{MHz}$ has been applied to the gaseous species shown in Fig. 2. Plasma etching of $\mathrm{SiO}_{2}$ employs fluorinated gas species such as $\mathrm{CF}_{4}, \mathrm{CHF}_{3}, \mathrm{C}_{2} \mathrm{~F}_{8}$, etc., in order to form a volatile product $\mathrm{Si}-\mathrm{F}$ with ionized fluorine atoms able to interact with silicon atoms on the wafer surface. The appropriate conditions cause continuous processes of ionization vs. recombination and excitation vs. relaxation. Therefore the optical emission spectroscopy is suited for monitoring and analyzing both the plasma-reaction chemistry and the practical applications based upon the processes that occur in plasma.
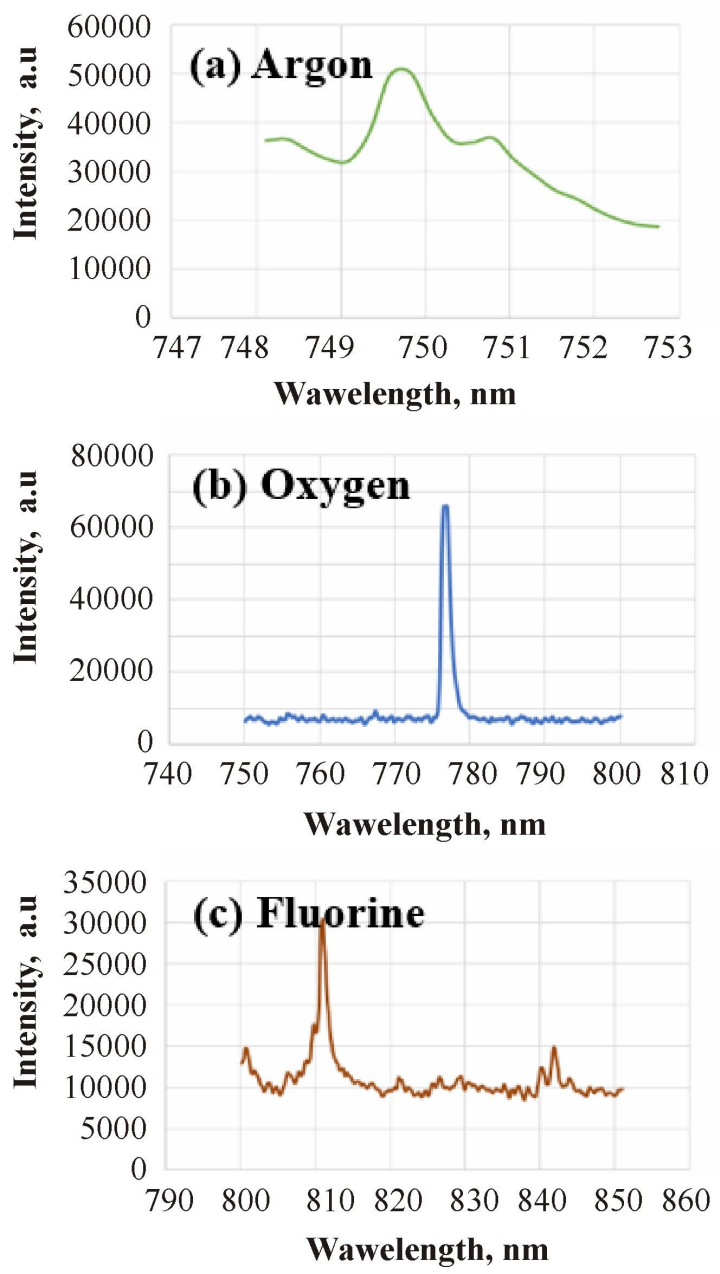

Fig. 2. Optical emission spectra corresponding to some gaseous species in their plasmic states.

Our optical-emission spectroscopy system consists of a collimator, an optical fibre, a spectrometer, and a computer for data processing and system controlling. One end of the fibre with the collimator is installed on a sidewall via a quartz glass viewing port, while the other end is connected to a spectrometer. It would be useful to have some global information on the plasma in a smaller region of the wafer; however, the field of view $30-40^{\circ}$ in a $300 \mathrm{~mm}$ wafer requires much wider fields of view close to $180^{\circ}$. 
Notice that makers of a $300 \mathrm{~mm}$ dynamic random memory or flash memory chips would like to have even more intimate plasma monitoring, e.g. from inside the very chamber, to alleviate plasma uniformity over large-size wafers. As a result, monitoring of plasma from inside the chamber would be desired, although installation of optical fibres in the plasma chamber requires cumbersome equipment modifications. A grating coupler based on silicon photonics, a waveguide, and an arrayed waveguide device can be a solution for monitoring spatially distributed plasmaemission intensity. Fig. 3 illustrates a conceptual scheme of our spatially resolved plasmauniformity monitoring sensor.

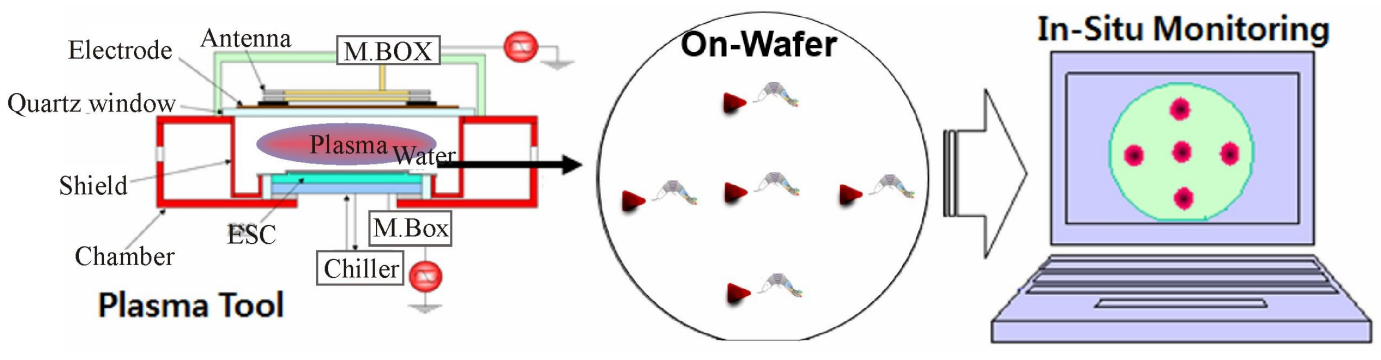

Fig. 3. Scheme of a sensor system for monitoring plasma uniformity. A silicon photonic device fabricated on a wafer is integrated with photodetectors to convert optical signals into electrical ones. Wireless communication with a controlling PC is preferred.

Usually, silicon photonics employs silicon-on-insulator wafers where silicon serves as a waveguide-core material and silicon oxide as a cladding one. However, this system manifests significant signal attenuation below and near the infrared wavelength region. On the other hand, plasma-glow discharge is located in the visible spectral range, and its spectrum depends on the chemical species in the plasma. Hence, we have employed silicon nitride and silicon oxide respectively for the waveguide core and cladding (see also our previous studies [9, 12]). Note that silicon-nitride core and silicon-oxide cladding have been continuously employed in the grating couplers addressed in the present study. Our silicon photonic device represents a grating coupler designed for collecting a vertical cross-section of the emission resulted from plasma-glow discharge in the wafer. The incident light can be diffracted when it comes to the surface of a periodic structure, and the Bragg condition describes the relationship between the wave vectors of the incident and diffracted waves. A Huygens-Fresnel principle helps to understand quantitatively how the Bragg-diffracted incident light transmits the optical signal.

The plasma-glow discharge includes a large collection of photon-electron energy transformations, although it appears as a simple planar light source available between two electrodes. The spectral lines of plasma emission lie in the visible spectral range (300-900 nm) and depend on the chemical species residing inside the chamber. Oxygen represents one of the common chemical species for monitoring $\mathrm{SiO}_{2}$ etching process. We have decided to design a silicon photonic device for collecting and transmitting the emission peak located at $777 \mathrm{~nm}$ (see Fig. 2b).

\section{Design and fabrication of device}

Our silicon photonic device includes waveguides and grating couplers. First, we have compared the optical transmittances of the silicon-nitride based optical device and a device built with a silicon-on-insulator technology. The simulation results shown in Fig. 4 correspond to such lighttransmitting materials as silicon and silicon nitride. To satisfy a single-mode transmission 

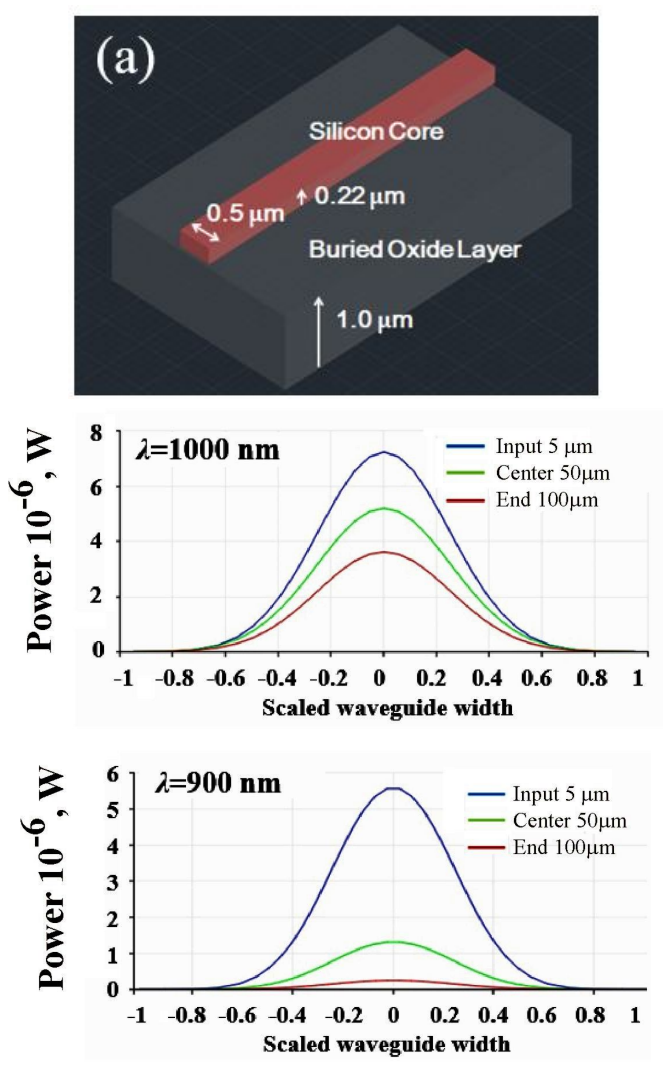
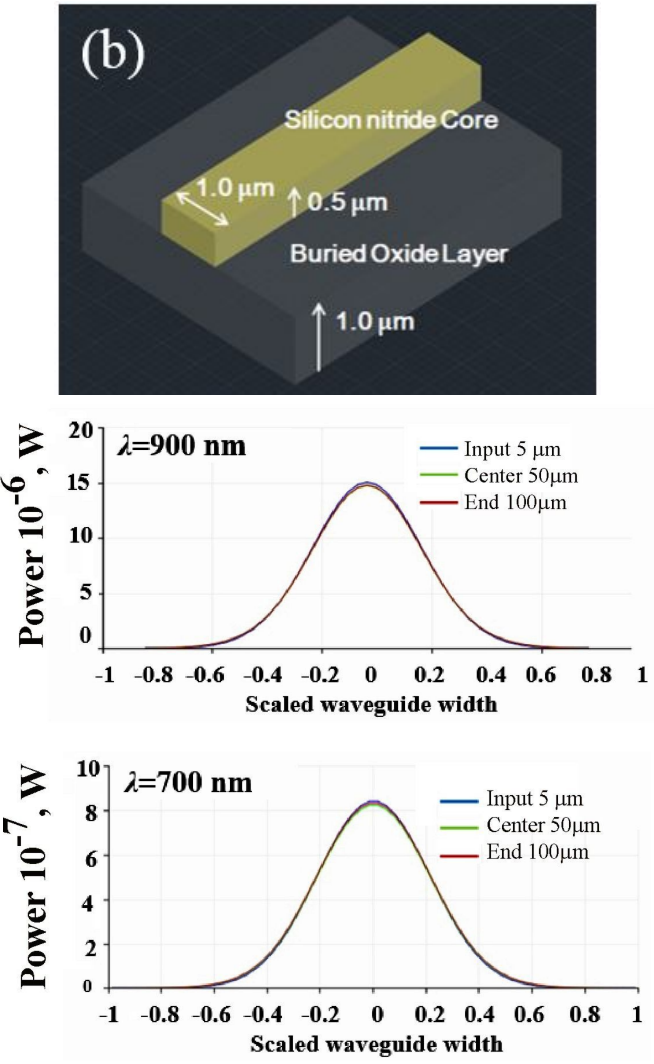

Fig. 4. Optical signal transmittances of strip-line waveguides: (a) silicon strip with silicon-on-insulator and (b) silicon-nitride strip line.

condition, we have taken the width $0.5 \mu \mathrm{m}$ of the buried oxide layer and its height $0.22 \mu \mathrm{m}$ (see Fig. 4a). Three points of optical-power monitoring located at the distances 5, 50 and $100 \mu \mathrm{m}$ from the light source have been simulated, with two different light-source wavelengths. When we deal with the light wavelength $\lambda=1000 \mathrm{~nm}$, the optical power is attenuated almost by half at the endpoint of the power monitor located at $100 \mu \mathrm{m}$. When the wavelength decreases down to $\lambda=900 \mathrm{~nm}$, the most of the power is attenuated and does not travel even some $50 \mu \mathrm{m}$. This implies that silicon waveguides are not appropriate for transmitting visible light. In a similar manner, we have also investigated the case of a silicon-nitride strip waveguide (see Fig. 4b). Here the width and the height are respectively equal to 1.0 and $0.5 \mu \mathrm{m}$, while the geometry for the single-mode transmission is modified properly. The light wavelengths amount to $\lambda=900$ and $700 \mathrm{~nm}$. We have observed almost no optical attenuation at the three monitor locations mentioned above (i.e., 5, 50 and $100 \mu \mathrm{m}$ ). This means that silicon nitride is suitable for monitoring plasma-emission light in the visible spectral range.

Second, we have studied the coupling efficiency of the silicon-nitride grating coupler with a conventional geometry, as illustrated in Fig. 5. The central light-source wavelength has been set to $\lambda=900 \mathrm{~nm}$ (Fig. 5b) and $\lambda=700 \mathrm{~nm}$ (Fig. 5c). Finite differential time-domain simulations have testified that vertical coupling of the plasma emission, especially for the oxygen-related peak located at $777 \mathrm{~nm}$, is feasible with the silicon-nitride grating coupler. The maximum $S_{21}$ value obtained for the source with $\lambda=700 \mathrm{~nm}$ seems to be smaller than that corresponding to $\lambda=900 \mathrm{~nm}$, although it can be improved by optimizing further the grating-coupler structure. 

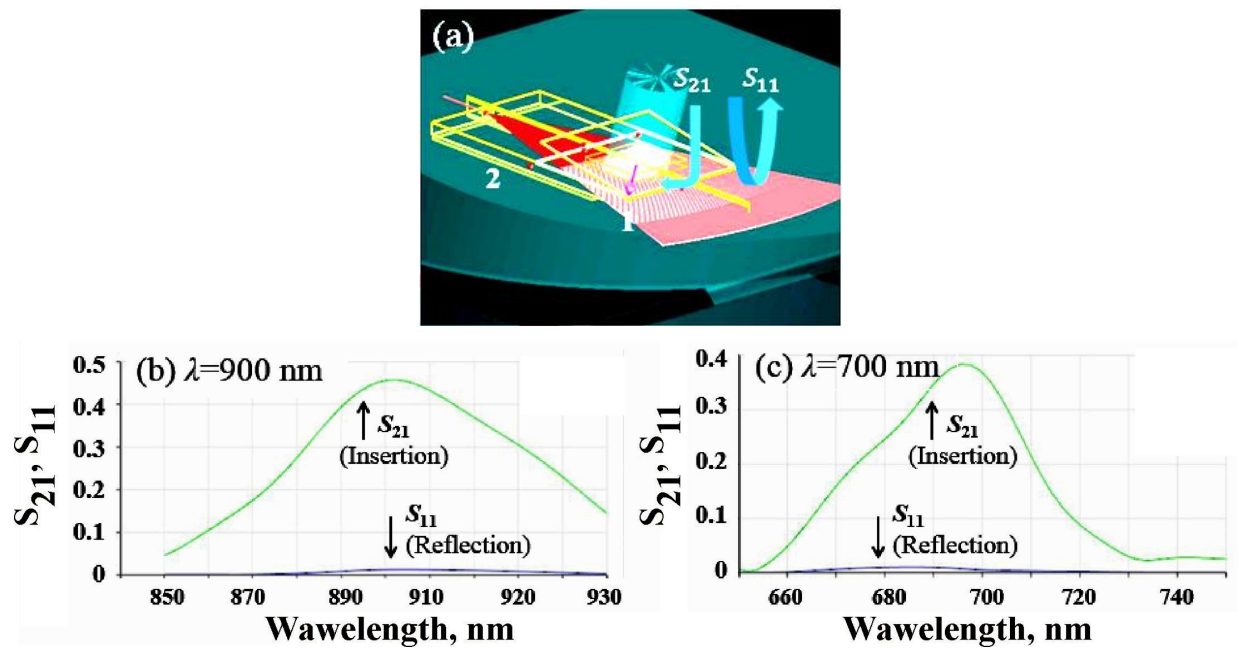

Fig. 5. Illustration of conventional grating coupler and its coupling efficiency expressed in terms of $S$-parameters for insertion $\left(S_{21}\right)$ and reflection $\left(S_{11}\right)$ : (a) a model of grating coupler used in the simulations; coupling efficiencies $S_{21}$ and $S_{11}$ obtained for the cases of input central wavelengths 900 (b) and $700 \mathrm{~nm}$ (c).

After that, we have optimized design of the device in terms of the thickness $t_{\mathrm{BOX}}$ of the bottom oxide cladding, the incident light angle and the grating period. In the grating couplers used for conventional purposes, the angle of light incidence is intentionally fixed at a few angular degrees to have a maximum coupling efficiency. However, the incident angle for the case of plasma emission cannot be fixed due to the nature of this collective emission that corresponds to numerous photons forming a spatially distributed light source. Nonetheless, we employ a hypothesis of coupling of the plasma emission, i.e. we suppose that a certain amount of the incident light is coupled and the rest of light is reflected or lost. To support this underlying hypothesis, we have investigated the $S_{21}$ parameter as a measure of coupling efficiency for the case of two different incident angles $\left(5^{\circ}\right.$ and $\left.9^{\circ}\right)$ and two different $t_{\text {BOX }}$ values $(2.1$ and $2.2 \mu \mathrm{m})$. The three-dimensional finite differential time-domain simulations have demonstrated (see Fig. 6) that the coupling efficiency at the incident angle $5^{\circ}$ is higher than that found for the case of $9^{\circ}$. This is
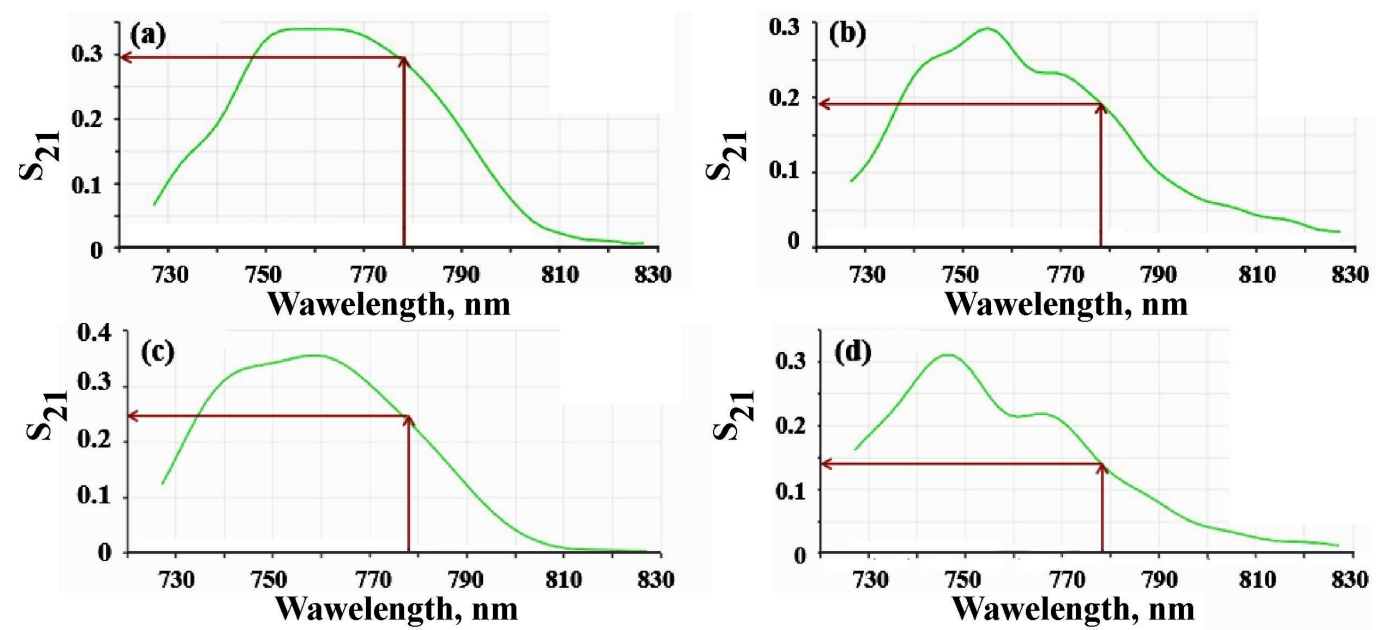

Fig. 6. Spectral dependences of $S_{21}$ parameter as a measure of coupling efficiency, as calculated for different incident angles $\theta$ and thicknesses $t_{\mathrm{BOX}}$ of a bottom oxide cladding: (a) $\theta=5^{\circ}, t_{\mathrm{BOX}}=2.1 \mu \mathrm{m}$, (b) $\theta=5^{\circ}$, $t_{\mathrm{BOX}}=2.2 \mu \mathrm{m}$, (c) $\theta=9^{\circ}, t_{\mathrm{BOX}}=2.1 \mu \mathrm{m}$, and (d) $\theta=9^{\circ}, t_{\mathrm{BOX}}=2.2 \mu \mathrm{m}$. Arrows indicate oxygen-related wavelength $777 \mathrm{~nm}$ under our interest.

Ukr. J. Phys. Opt. 2018, Volume 19, Issue 4 
well matched with the coupling characteristics of a conventional grating coupler, which manifests a maximum coupling efficiency nearby the incident angle $3^{\circ}$. Note that we still have some nonzero amount of the coupling at the incident angle of $9^{\circ}$. The reason is that the 'plasma-emission source' cannot be treated as a point one. Moreover, it does not correspond to a fixed incident angle. Thus, unlike conventional grating couplers used in many applications, we deal with some region of the incident angles. For the emission wavelength $\lambda=777 \mathrm{~nm}$ associated with oxygen atoms (namely, excited oxygen radicals), the $t_{\mathrm{BOX}}$ parameter $2.1 \mu \mathrm{m}$ provides a higher coupling efficiency than that found for larger $t_{\mathrm{BOX}}$ values.

Fig. 7a displays a cross section of our silicon photonic grating coupler. Here $\Lambda$ is the coupler period, and the fill factor $f f$ denotes the ratio of the tooth and coupler periods. The depth of the tooth is determined by the etched depth of the core material. The other design parameters are functions of the coupler period, as well as the type and the thickness of the covering material. The device should be properly designed in order to collect selectively a desired spectral emission line.

Assume that the grating coupler is infinite along horizontal direction to satisfy the Bragg condition. Its effective index is given by $n_{\text {eff }}=f f n_{\text {eff } 1}+(1-f f) n_{\text {eff } 2}$, where $n_{\text {eff } 1}$ and $n_{\text {eff } 2}$ denote the effective indices of the grating tooth and the slot. Then the coupler period becomes $\Lambda=\lambda /\left(n_{\text {eff }}-\right.$ $\left.n_{c} \sin \theta\right)$, where $\lambda$ is the wavelength of the incident light and $n_{c}$ the refractive index of the cladding. The typical parameters used in this study are as follows: $n_{\text {eff }}=1.63, n_{\text {eff } 1}=1.79, n_{\text {eff } 2}=1.44$, $n_{c}=1.45$, and $f f=0.55$. Fig. $7 \mathrm{~b}$ and Fig. $7 \mathrm{c}$ show the coupling efficiency obtained for different coupling periods and incident angles. These results have led us to further studies on the coupling efficiency as a function of the incident angle $\theta$ and the coupling period $\Lambda$ (see Fig. 8). The grating coupler collects plasma-emitted photons so that it integrates the light emitted at different injection angles. We observe the largest amount of plasma emission under the conditions corresponding to Fig. 8d. Therefore these conditions determine the optimized design of our grating coupler. In particular, the optimization implies the equalities $t_{\mathrm{BOX}}=2.1 \mu \mathrm{m}$ and $\Lambda=0.54 \mu \mathrm{m}$.
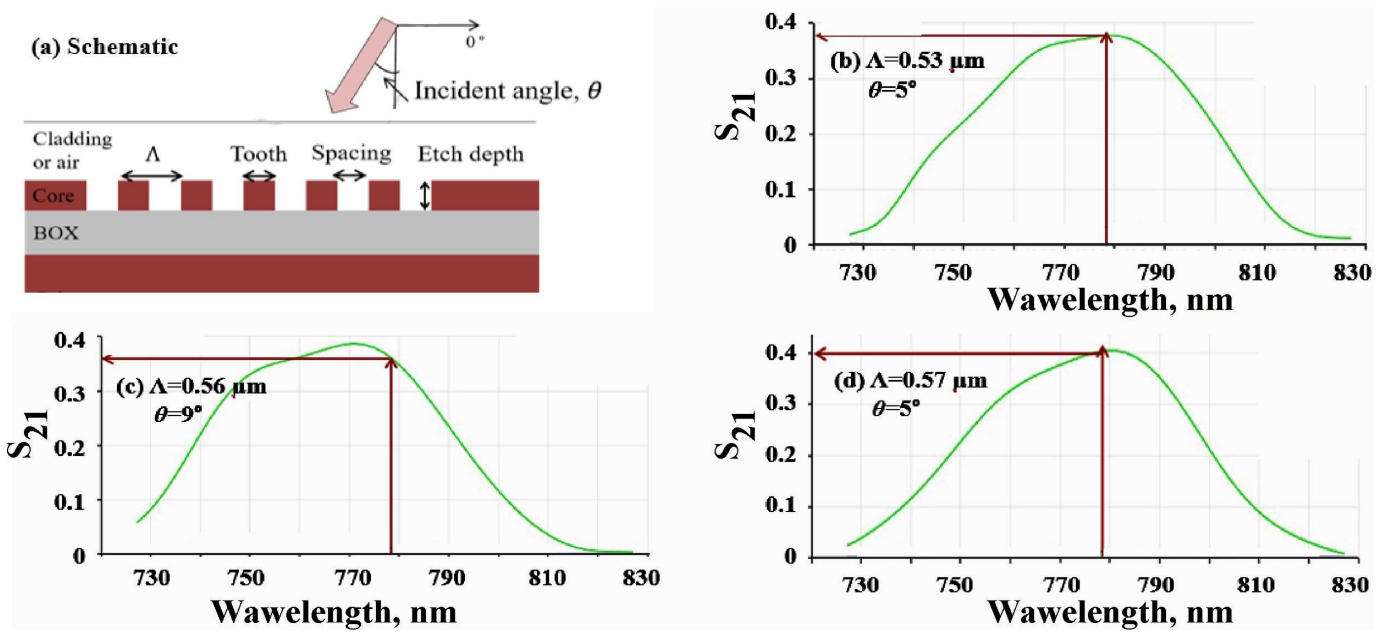

Fig. 7. Scheme of our grating coupler (a), and spectral dependences of $S_{21}$ calculated for different coupling periods $\Lambda$ and incident angles $\theta$ : (b) $\wedge=0.53 \mu \mathrm{m}, \theta=5^{\circ}$, (c) $\wedge=0.56 \mu \mathrm{m}, \theta=9^{\circ}$, and (d) $\wedge=0.57 \mu \mathrm{m}, \theta=5^{\circ}$. Arrows indicate oxygen-related wavelength $777 \mathrm{~nm}$.

Our grating coupler represents a surface coupler aimed at collecting the incident plasmaemission light along the vertical direction. Its coupling efficiency depends on the thicknesses of cladding and core, as well as the grating period set during micro-fabrication. It is known that even 
small deviations from the proper technological processes of depositing thin films, photolithography or dry etching can jeopardize the coupling efficiency of a grating coupler. As a consequence, we have improved fabrication of our device in terms of process integration. We define, somewhat conventionally, two 'tracks' of this integration (see Fig. 9): one is a microfabrication process based on 6-inch wafer with electron-beam lithography, and the other corresponds to a semiconductor-fabrication process on 8-inch wafer with $\mathrm{KrF}$ lithography $(\lambda=248 \mathrm{~nm})$.
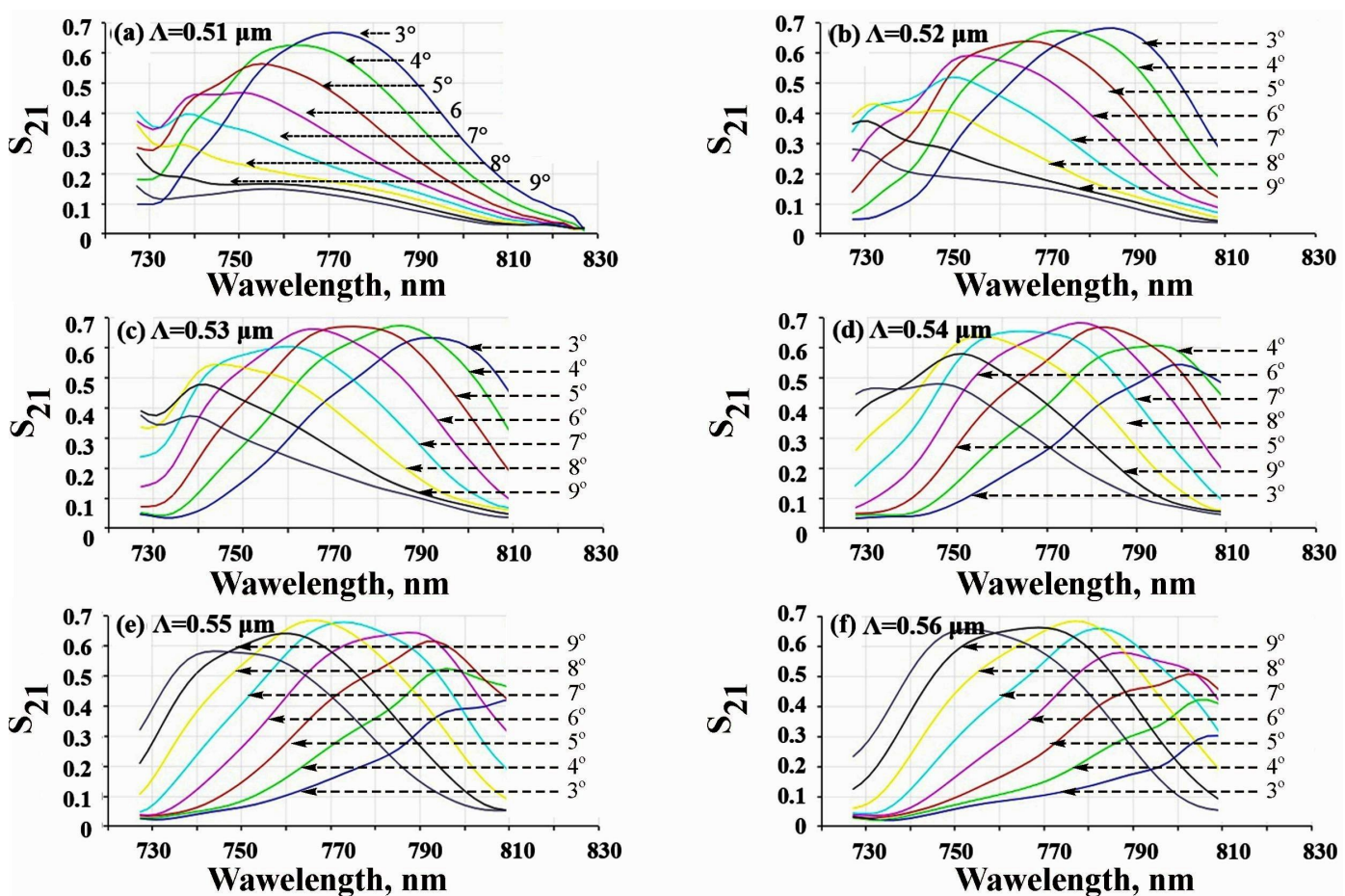

Fig. 8. Spectral dependences of coupling efficiency $S_{21}$ calculated for different coupling periods and incident angles (see the legend).

\section{Process of Integration of the Grating Coupler}
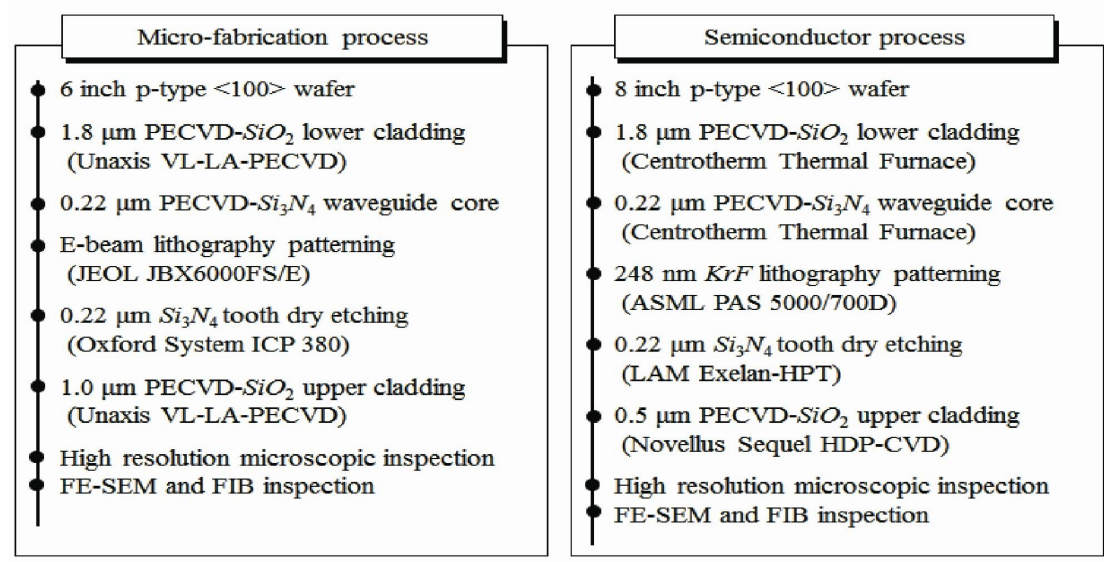

Fig. 9. Two stages of our integrated method for fabricating grating coupler: FE-SEM, field-emission scanning electron microscopy; FIB, focused-ion beam; ICP, inductive coupled plasma; PECVD, plasma-enhanced chemical vapour deposition; HDP-CVD, high-density plasma-chemical vapour deposition. JEOL and ASML are the names of equipment vendors.

Ukr. J. Phys. Opt. 2018, Volume 19, Issue 4 
The micro-fabrication is suitable when producing a small quantity of devices because then the electron-beam lithography can replace the photolithography which represents much more expensive and advanced technology. Moreover, the problem of uniformity can also be overcome in the case of small-sized wafers. However, the electron-beam lithography technology still remains relatively expensive, owing to a great number of scribing lines in the grating coupler.

The second 'fabrication track' (see Fig. 9) employs KrF lithography for deep submicron-size patterning. In this work, the critical dimension of the grating coupler is equal to $238.5 \mathrm{~nm}$, so that the $i$-line stepper cannot support patterning repeatability for our geometrically sensitive grating coupler. During the dry etching process within the both tracks, the dry-etch profile of the tooth patterning is the most challenging process because the process of collection of light and the light transmittance of the grating coupler can easily be changed by either the shape or the size of the patterned grating. Therefore a precise etch control is required for fabricating the silicon photonic grating coupler. Examples of the devices fabricated as described above are presented in Fig. 10.

(a) Micro-fabrication process
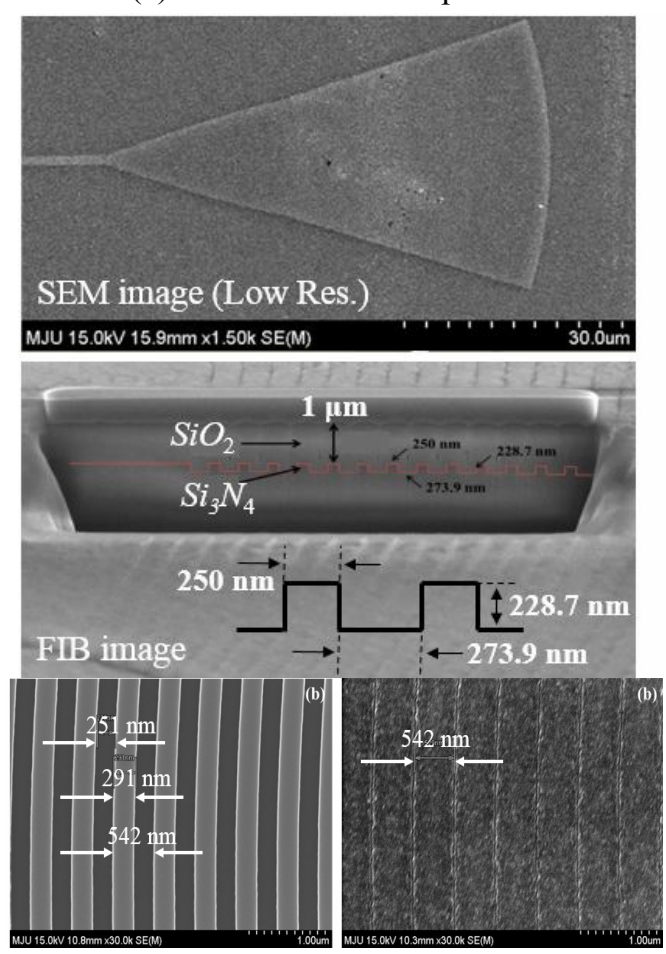

(b) Semiconductor process
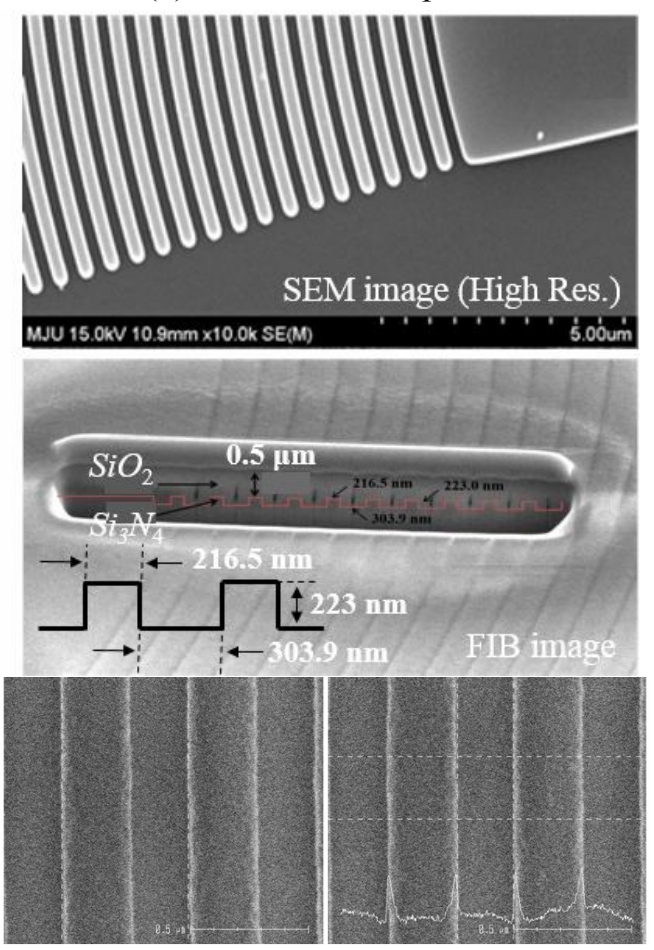

Fig. 10. Examples of grating couplers fabricated using the integrated processes shown in Fig. 9.

\section{Conclusion}

In the present study, we propose a design and fabrication of the silicon photonic grating coupler chip, which is used for in-situ monitoring of plasma emission in semiconductor etch domains. The device is based on the silicon-nitride core and the silicon-oxide cladding, thus providing a satisfactory transmittance of the visible light collected from the emission of vacuum plasma. We have studied the coupling efficiency of the grating coupler depending on such geometrical parameters of the grating coupler as the grating period, the fill factor and the etch depth. Basing upon the finite differential time-domain simulations, we have shown that the grating coupler with the thickness $t_{\mathrm{BOX}}=2.1 \mu \mathrm{m}$ of the bottom oxide cladding and the coupling period $\Lambda=0.54 \mu \mathrm{m}$ can 
detect a wide range of incident plasma emissions. Besides, we have investigated the feasibility of our silicon photonic device. The two kinds of fabrication technology have been considered for this aim. Our future work will include fabrication of the device and the appropriate functional measurements performed in a vacuum chamber.

\title{
References
}

1. Dalton T J, Conner W T and Sawin H H, 1994. Interferometric real-time measurement of uniformity for plasma etching. J. Electrochem. Soc. 141: 1893-1900.

2. Buie M J, Pender J T, Soniker J and Brake M L, 1995. In situ diagnostic for etch uniformity. J. Vacuum Sci. \& Technol. A. 13: 1930-1937.

3. Wum B, Kumar A and Pamarthy S, 2010. High aspect ration silicon etch: A review. J. Appl. Phys. 108: 051101.

4. Lee C G N, Keren Kanarik J and Gottscho R A, 2014. The grand challenges of plasma etching: A manufacturing perspective. J. Phys. D: Appl. Phys. 47: 1-9.

5. http://electroiq.com/blog/2016/08/evolution-of-across-wafer-uniformity-control-in-plasma-etch/

6. Oh C, Ryoo H, Lee H, Kim S, Yi H and Han J, 2010. Spatially resolved optical emission spectroscopy for analyzing density uniformity of semiconductor process plasma. Rev. Sci. Instrum. 81: 103109.

7. Kim I $J$ and Yun I, 2016. Plasma process uniformity diagnostics technique using optical emission spectroscopy with spatially resolved ring lens. IEEE Trans. Industrial Electron. 63: 5674-5681.

8. Zhu Y, Jiao Y, Wang J, Xie W, Tian B and Van Thourhout D, 2015. Ultra-compact silicon nitride grating coupler for microscopy system. Symposium of the IEEE Photonics Society. Brussels (Belgium), 55-58.

9. Hwang S, Lee M, Kim S and Hong S, 2017. Characterization of silicon nitride-cored silicon photonics waveguide material for optical microring resonator. J. Nanoelectron. Optoelectron. 12: 903-907.

10. Kim B and Hong S, 2014. In-situ virtual metrology for the silicon-dioxide etch rate by using optical emission spectroscopy data. J. Korean Phys. Soc. 65: 168-175.

11. Jang B and Hong S, 2018. Spectroscopic analysis of film stress mechanism in PECVD silicon nitride. Trans. Electrical and Electronic Mater. 19: 1-9.

12. Ali S A and Hong S, 2017. Compact arrayed waveguide gratings for visible wavelengths based on silicon nitride. Ukr. J. Phys. Opt. 18: 239-248.

Minhee Lee, Sung Chul Kim and Sang Jeen Hong. 2018. Silicon photonic grating coupler for monitoring optical emission of plasma. Ukr.J.Phys.Opt. 19: $244-253$.

doi: $10.3116 / 16091833 / 19 / 4 / 244 / 2018$

\begin{abstract}
Анотація. Розроблено і виготовлено оптичний хвилевод та тратковий пристрій зв'язку на основі кремнієвої фотоніки. Прилад призначений для контролю спектральної лінії 777 нм плазми кисню, яка відповідає електронній релаксаиї атомів кисню в плазмі. Для забезпечення максимальної ефективності поверхневого зв'язку оптимізовано товщину оболонки з оксиду кремнію та геометрію траткового пристрою зв'язку на основі моделювання за методом скінченних приростів у часовій області. Для виготовлення кремнієвої фотонної мікросхеми використано два способи - мікро-конструювання за методом електронно-променевої літографії та процес формування напівпровідників, що базується на оптичної літографії за технологією 248 нм. Запропонований пристрій зв'язку можна використовувати як концептуальний підхід до створення приладів накопичення фотонів на підкладиі, призначених для вивчення плазми тліючого розряду.
\end{abstract}

Ukr. J. Phys. Opt. 2018, Volume 19, Issue 4 